\title{
The Application of Imitation in the Improvement of English Writing for ESL Learners
}

\author{
Xiaoqin Guan \\ Xiamen University, TKK, Zhangzhou, Fujian, China
}

Keywords: Imitation; English Writing; Critical Thinking.

Abstract: English writing skill is an important manifestation of a person's language proficiency and at the same time it is also a skill hard to be grasped for most ESL learners. This paper aims to improve students' writing ability through the application of imitation, which includes the replacements of vocabulary, sentences and paragraphs. And the technique of imitation is closely connected with critical thinking. Successful imitation practices may result in better understanding of native writer's way of thinking and thus they can also produce sentences or essays using authentic and idiomatic language.

\section{Introduction}

English writing skill is an important manifestation of a person's language proficiency and at the same time it is also a skill hard to be grasped for most ESL learners. English writing is a process of creation and discovering, which, generally speaking, consists of the ability to use language and the ability to write logically and systematically.

The improving of language ability lies in the use of vocabulary and sentence patterns. Virtually, the use of vocabulary does not equal the English words acquired. Instead, it involves the definite comprehension of the context of the words. And having a good command of English sentence patterns does not equal the knowledge of grammar. It refers to the flexible use of different sentence patterns to express oneself freely. Logical thinking is closely connected with a person's life experience, education background and mindset deeply rooted due to their culture background. Therefore, when ESL learners start to write in English, this is the biggest obstacle they may encounter. Most of them don't know how to write more efficiently. Even if they try very hard to produce an essay, problems, such as a small vocabulary, simple sentence patterns, wrong use of grammar, wrong word order and a loose structure are not difficult to be found. Then how to deal with these problems mentioned above? The answer may be found in the imitation exercises of excellent sentence patterns and passages from those written by native writers. Both problems can be solved all at once.

The wealth of experts and scholars have been committed into the study of theories concerning the improvement of writing skills. "Writing is learned by imitation. If anyone asked me how I learned to write, I'd say I learned by reading men and women who were doing the kind of writing I wanted to do and trying to figure out how they did it.(Zinsser, On Writing Well,2006 )" Throughout the history of research on language teaching, both input and output have been the focus of discussion among teachers and researchers. It is noted that language learners need enough input to come to the 
level of output and only a great amount of input can ensure quality output. Classical English materials, imitation and internalization is the only way to the improving of English writing (Liu Kehong, 2011:67). Li Cun(2011) combined the learning theory and strategy of imitating and adopted a strategy of inquiry learning method. It is proved by their study that students' proficiency in language correlates with the frequency of those materials written by native writers. This paper tries to explore the application of this theory in the empirical teaching. Most of the materials used in this paper come from the third edition New Horizon College English, from book one to book four.

\section{The Imitation of Sentences in Writing}

Sentences are the basic element of a passage. Only when a person can write good sentences can he or she be able to write good essays. Imitation enables a learner to internalize the sentence patterns and structures from those classical materials, and finally be proficient in English writing. In order to advance gradually in due order, there are two ways to approach imitation of sentences: replacement of vocabulary and extracting sentence patterns.

\section{Replacement of Vocabulary}

For beginners of language learning, replacement of vocabulary is the first step towards writing. Under the instruction of teachers, English learners can try to create different contexts in their minds in accordance with their real life. In this way the original pattern can be used adeptly. And they can move from the easy to the difficult and more complicated step by step.

"The hundred years since the Battle of Waterloo had not been entirely free of disaster - there had been a horrific civil war in America, some regional scraps in Asia, the Franco-Prussian war and the occasional colonial calamity. But continental peace had prevailed. Globalization and new technology - the telephone, the steamship, the train - had knitted the world together. "The italicized part can be used in the discussion of topics related to globalization. However, since we are now in the twenty-first century, we can replace "the telephone, the steamship, the train" with "5 G". Then we can produce a sentence like "The world is changing at a staggering rate. Globalization and new technology $-5 \mathrm{G}$ - had knitted the world together. And it promises to transform our life."

Another example comes from "Toward a brighter future for all"(Unit 1, Book 1). "As president of the university, I am proud to welcome you to this university. Your achievement is the triumph of years of hard work, both of your own and of your parents and teachers." The italicized part can be used to talk about the good results especially after a long period of time's hard work. Thus we can replace "achievement" with other words like "honor, award, status, position, and etc."

When talking about fear, we can refer to a sentence in Unit 2 of Book Three - "Swimming through fear". The sentence goes like this "I shivered with fear. Nothing scared me as much as water." Instead of "water", we can also fill in things that make us scared, like "a public speech, a confined room, a Roller Coaster, etc."

When we need to discuss the two sides of a matter, we can imitate a sentence from New Concept English Book 4: "As is often pointed out, Knowledge is a two-edged weapon which can be used equally for good or evil". This sentence pattern is indeed useful if we want to talk about things like "nuclear energy, gene engineering and international trade, etc." For example, we can write "As is pointed out by some experts, the international trade war between China and America is a two-edged weapon which can be used equally for good or evil."

In Unit 5 of Book 1, Cliff young, an unlikely hero, we came across a sentence about his brilliance. "To this day, Cliff Young remains a magnificent reminder and brilliant example of how ordinary individuals can inherently achieve remarkable results." We can use this sentence to describe anyone who is a normal person but make unusual contribution to our society. The only thing needed to be 
done is to replace the name in the sentence.

\section{Replacement of Sentences}

Replacement of sentences is based upon replacement of vocabulary and it takes a step forward which is of higher difficulty and more efficient in the training of writing. When ESL learners are doing such practices, they need to analyze the sentences more accurately, and understand the logical relations embraced in the sentences. Then they can come up with a sentence pattern that can be applied in other contexts.

How to write an opening sentence? We can refer to a sentence in Unit 7 of Book four. "Ever since then, with the rapid increase of population density, the industrialized world's thirst for energy has more than tripled." This is declarative knowledge. To make it possible to use creatively, however, we have to convert it into procedural knowledge as follows: "With the rapid increase / development of X, Y's thirst / demand for Z triples / doubles". We can produce other sentences like "With the rapid development of networking technology, the world's demand for IT talents has tripled." Or "With the rapid increase of juvenile crime rates, the society's thirst for adolescent mental health education has doubled".

Then how to come up with a sentence to end an essay? In Unit 2 of Book 4, the confusing pursuit of beauty, we can find a sentence in the concluding part. "Anyway, to get back to my original point: If you're a man, and a woman asks you how she looks, you can't say she looks bad without receiving immediate and well-deserved outrage." Normally when writing for a conclusion in an essay, ESL learners use "to sum up, all in all, ...", expressions like this. However, the italicized part is a smart use of words to echo the statement at the very beginning and at the same time emphasizes on the author's point of view. Other examples are like this "Anyway, to get back my original point: Parents should not spoil their children by showering them with too many material things."

Let us take a look at this sentence from Unit 5 of Book 3: "People are labeled as workers if their personal interests coincide with the jobs society pays them to do; what is necessary labor from the point of view of society is voluntary play from the individual's personal point of view." The italicized part concisely expresses a contrasted point of view. Basing on this pattern "What is A from the point of view of $B$ is $C$ from the point of view of $D$.", we can produce many other sentences. "What is meat from the point of view of one man is poison from the point of view of another man.", or "What is weird dressing from the point of view of elderly people is fashion from the point of view of young people."

In Unit 1 of Book 3, we find a inspiring sentence. "They attained success, not because it was easy, but because they had the will to overcome profound obstacles and to work diligently in the pursuit of their goals." How to convert it into a pattern? This sentence is used to differentiate between cause and effect. Thus we have "X does Y, not because/because of ..., but because/because of ..." We can produce sentences like "The environment is deteriorating, not because of the pollutions caused by industry emissions, but because of public's poor sense of environmental protection." or "He failed in business, not because of misfortune, but because of his own error in decision making."

In Unit 4 of Book 3, we find another sentence about cause and effect, using a different structure. "According to research, the experience of an exotic culture endows us with a valuable open-mindedness, making it easier to realize that even a trivial thing can have multiple meanings." A pattern can be extracted as "According to A, B endows/ infects C with D, (thus/thereby) making it easier/ harder to do E". we can write "According to research, the experience of failure endows us with more of rational thinking, thus making it easier to realize the truth that a bad thing can be turned into a good one." Or "According to evidence, contact with the bad infects a child with the same vice, thereby making it harder to lift him out of it." 
When we come to describe a respectable person who achieved great success, we can use this sentence from Unit 3 of Book 4. "Recognized as an outstanding entrepreneur with an agreeable and winning personality, Smith is held in high regard by his competitors as well as his employees and stockholders." We have to convert it into procedural knowledge as follows: "Recognized / Regarded / Deemed as X with Y, Z is held in high regard". For example, we can write "Recognized as God of Basketball with breathtaking skills as well as a strong competitive spirit, Michael Jordan is held in high regard by his rivals, teammates and coach", or "Regarded as an excellent teacher with extensive knowledge, good manners and professional ethics, Li Xiaowen, the "Sweeping Monk" of THU, was held in high regard by his students and colleagues".

When making comparisons, we can refer to a sentence in Unit 6 of Book 4. "I could no more imagine growing up to become one of these sophisticated people than I could imagine becoming a sovereign prince." How to convert it into a productive pattern? We can produce a pattern like this: $\mathrm{X}$ could no more do / be $\mathrm{Y}$ than $\mathrm{X}$ could do / be $\mathrm{Z}$. Thus, we have more examples like "The scientists could no more change the law of nature than they could have the sun rise in the west." Or, "We could no more bear the consequences of environmental pollution than we could go through a long winter without sunlight."

When we are connecting two clauses, we need to use some conjunctional words, like, what's more, more importantly. They can be used to attract readers' attention to the next subject. Now let us take a look at examples from Unit 4 of Book1: "We count on first responders to rush toward danger, especially when it involves us or those we love." Or "We honor the fireman, the policeman, and the average citizen by recognizing their heroism. Perhaps, even more importantly, we honor them by working to change the circumstances that led to their death." We can extract patterns like "Sb. do sth., especially when...." "Sb. do sth. by... . Perhaps, even more importantly, sb. do sth. by...". Thus we can produce sentences with similar structures. "I love recalling things and persons in the past, especially when I grow older and when loneliness strikes me at night." "There are two types of laws: just and unjust. Every individual in a society has a responsibility to obey just laws and, even more importantly, to disobey and resist unjust laws."

With the help of these useful sentence patterns, English learners can produce equally beautiful sentences easily.

\section{Paragraph Imitation}

Through the imitation of paragraphs, we can learn and be familiar with its basic structure, the way these sentences are expanded and how they are linked together in a logical way. After practicing many times, ESL learners can eventually master the technique of organizing their thoughts and produce essays with clear organization and logic.

A paragraph is not just a random combination of sentences. It requires coherence and logical integrity between sentences, and each paragraph only can focus on one point. Normally a paragraph consists of a topic sentence, developing sentences and concluding sentence. The topic sentence gives a paragraph direction and purpose. It tells what the paragraph is about and how the writer will develop that topic. Developing sentences are the main body of a paragraph and all of them need to support the topic sentences. These sentences need to be structures in a logical way with the help of linking words or phrases. The concluding sentence emphasizes the main idea by echoing the topic sentence.

Different from us who think in the spiral way, they tend to think in the linear way. As far as paragraph writing is concerned, deduction is typical of their linear way of thinking. The following paragraph is a typical example from Unit 1 of Book 1:

For you, these next four years will be a time unlike any other. (Topic sentence) Here you are 
surrounded by great resources: interesting students from all over the country, a learned and caring faculty, a comprehensive library, great sports facilities, and student organizations covering every possible interest from the arts to science, to community service and so on. (Detail 1: What is available to you on campus) You will have the freedom to explore and learn about new subjects. You will learn to get by on very little sleep, meet fascinating people, and pursue new passions. (Detail 2: What you can do) I want to encourage you to make the most of this unique experience, and to use your energy and enthusiasm to reap the benefits of this opportunity. (Concluding sentence)

Following this model, we can write other paragraphs on a topic like "How to choose a suitable university." Sample paragraph:

When choosing a university, you must consider some key factors. (Topic sentence) The most important factor is whether the university can prepare you well for your future. It should provide up-to-date courses and have qualified professors. (Detail 1) Another factor is affordability. You need to be able to afford the tuition fees and living expenses. Some schools offer scholarships to outstanding students or to those who cannot afford the tuition fees. (Detail 2) Finally, a good location is also important. An ideal school should be located in a quiet place and have convenient public transport. (Detail 3) You should consider these factors carefully in order to find the most suitable university. (Concluding sentence)

As far as paragraph writing is concerned, exemplification is another typical linear way of thinking, as shown in Unit 4 of Book 1 from Paragraph 1to 4:

[Question] Who's a hero these days? (Para. 1)[Example 1] Daniel Hernandez courageously ran through the danger in a mass shooting and saved his boss and friend, Gabrielle Giffords. (Para. 2)[Example 2] In the mass shooting, Dory Stoddard saved his wife by falling on top of her to shield her from the hail of bullets. (Para. 3)[Conclusion] Both Daniel and Dory are civilian heroes, who acted out of instinct with courage and grace. (Para. 4)

This pattern can be used to explain to readers a concept or a phenomenon, like "a culture shock".

(Question)What is a culture shock? (Example)When he first visited the US, for example, Mr. Li was confused on a bus. He offered his seat to an elderly man, but the man seemed annoyed and refused to take the seat. Later, Mr. Li's American friends explained to him that in the US it is not advisable, and even offensive, to offer your seat to elderly people. This custom is very different from that in China, where people are encouraged to do so. [Conclusion] From the example we can see that culture shock is the feeling of confusion and anxiety when you encounter situations to which the cultural norms in your culture are no longer applicable.

Finally, let's take a look at another example of cause and effect from section A of Unit3 of Book1: College life in the Internet age.

Example:

I have been doing regular exercise since my doctor told me to do so a few years ago. (Cause) As a result, my physical health has much improved. (Effect 1) I was overweight and had high blood pressure. But after exercising every day for half a year, I have lost 15 pounds and my blood pressure remains stable now. (Detailed explanation) Besides, exercising regularly has also benefited my mental health because it helps me release anxiety. (Effect 2) I used to get nervous very often and have a hard time getting to sleep. But now I become more relaxed because regular exercise takes away much of my daily stress, and I sleep well now. (Detailed explanation)

Following this pattern, we can choose another topic "Teenager smoking". The effect is that it is not uncommon to see teenagers smoking today. And we analyzes that the causes are peer pressure and imitating adults. So we can write an essay like this.

It is not uncommon to see teenagers smoking today. (Effect) Some of them smoke because of peer pressure. (Cause 1) When they see some of their friends smoking, they feel the pressure to try 
it out in order to "fit in" with the crowd. (Detailed explanation) Some other teenagers smoke because they want to imitate adults or appear to be more mature. (Cause 2) Teenagers like to imitate their favorite stars and adults around them. So, parents who smoke may set a bad example for their children. (Detailed explanation) In conclusion, the causes of teenager smoking can be attributed to peer pressure and their intention to look like adults. (Concluding sentence)

\section{The Integration of Critical Thinking}

Imitation does not really mean blind imitation. Through the practice of imitation, learners must at first read through the original text thoroughly, and then came upon with questions to help themselves understand the text better. Learners cannot just accept everything they read; instead they need to analyze the relations between each sentence or each part to see how they are integrated as a whole essay. Then they can extract patterns and relate them to their actual writing practices.

Without correct guidance, learners may have great defect in "the depth of thoughts, the structure of knowledge and the ability to analyze problems"(Hu Wenzhong, Sun Youzhong, 2006). Therefore, in the teaching of writing, imitation technique has to be combined with critical thinking which has something to do with reasoning and logical thinking. At every stage of writing, learners need to apply reasoning to describe, analyze and assess the materials and then to provide details to support their arguments. First of all, teachers can provide three to four passages related to the same topic written by different native writers, and then guide students to analyze the passages from four perspectives like the strictness of argumentation, reliability of arguments, ambiguity of words and sentences and rationality of conclusions. They learn to write articles to express their original ideas based on the assessment of other's arguments. Teachers should encourage students to raise questions. Through reflection and hypothesis, then verification of these hypothesis using logical argumentation and the ability to solve problems, critical thinking ability can be improved a great deal. Second, teachers themselves need to understand the value of "Give a man a fish and you feed him for a day; teach a man to fish and you feed him for a lifetime." And the role of teachers is changing from imparting knowledge to stimulating thinking. They act as a prompters and participants, organizers, directors, instructors, and facilitators. Teachers are not the only authority. In the teaching environment, students are pushed to raise effective questions and to explore rationality. Third, teachers need to select proper materials for students to read. It's better that the topics chosen are enlightening, open, and controversial. And at the same time they can spark students' interest. Recommended materials include New Horizon College English Text Book (the Third Edition), New Concept English, and the Economists. New Horizon College English textbooks are used by a lot of Chinese College, and all of the texts are from magazines, newspapers in English -speaking countries. New Concept English is a classic teaching material for most English learners. It contains wealth of classical usage of words, sentences and paragraphs. Many journalists working for The Economists come from different fields like history, philosophy, law, science and etc. They have deep cultural accumulation and are masters of word and sentence-making and logical argumentation. Articles written by them are very good examples Finally different from the traditional teaching method, teachers do not provide all the learning materials to the students. They should learn to have access to information they need and they should possess the ability to quickly locate the needed information. Students' autonomous learning is a very crucial link of the whole learning process.

\section{Conclusion}

Imitation of classic English works is the only effective way to high level of writing. We all know that language is closely associated with people's mode of thinking. Successful imitation practices may result in better understanding of native writer's way of thinking and thus they can also produce 
sentences or essays using authentic and idiomatic language.

\section{References}

[1] Cottrell, S. Critical Thinking Skills: Developing Effective Analysis and Argument [M]. New York: Palgrave Macmillan, 2005.

[2]Vallis, G. L. Reason to Write: Applying Critical Thinking to Academic Writing [M]. North Carolina: Kona Publishing and Media Group, 2010.

[3]Zinsser, W. On Writing Well - an informal guide to writing nonfiction[M]. New York: Harper \& Row, Publishers, 1976

[4]Hu Wenzhong, Sun Youzhong. On Strengthening humanistic education in the English language curriculum [J]. Foreign Language Teaching and Research. 2006, 38(5): 243-247.

[5]Li Cun. Study On the Problems of the Strategy of Adopting Inquiry Imitating Learning Method in English Writing[J]. Journal of ZhaoTong University. . 2011.04

[6] Liu Kehong. A minimum and effective writing strategy of the teaching of college English writing based on the imitation of classic English[J]. Journal of Tianjin Foreign Studies University. 2011.03 